\title{
Adoption of Innovative Education Strategies to the Needs of the Time: A Case Study of Ritsumeikan Asia Pacific University (APU)
}

\author{
PISHV A Davar \\ Ritsumeikan Asia Pacific University, Beppu City, Oita Prefecture, Japan \\ Email: dpishva@apu.ac.jp
}

\begin{abstract}
In our modern era of Internet, mobile and digital information technology, adoption of innovative education strategies to the needs of the time is quite important particularly at private educational institutions which cater to economically affluent students who are becoming picky and often more interested in their distractions than in their studies. Ritsumeikan Asia Pacific University (APU) which was established in the year 2000 with an aim of becoming a hub for shaping the future of Asia-Pacific region by creating world class leaders in science, management, and economics through a bilingual curriculum, international under-standing, promotion of freedom, peace, humanity, and sensitiveness to the needs of the time, has integrated multimodal approach towards enhancing the quality of teaching and learning, and provides a total student support and care system. As a millennium university, it is equipped with state-of-the-art classrooms and tries to enhance its educational endeavors through proper use and efficient adaptation of educational technologies into its teaching pedagogies. However, due to being a private university and charging handsome tuitions fees, it has been attracting some of the most affluent students onto the campus, many of whom are often more interested in their distractions than in their studies. The decline in youth population and the economic slowdown in Japan have also adversely affected the quality of incoming students. This paper attempts to explain how APU tries to assure quality of their graduates despite the abovementioned problems through blended learning, peer knowledge sharing, adaptation of Blackboard (Bb, the most commonly implemented Web-based learning management system), portfolio, active learning, student support, academic advising, and by providing of a natural learning environment.
\end{abstract}

Index Terms - Active Learning, Blackboard, Bb, elearning, Learning Management System, LMS, Learning Commons, Portfolio

\section{INTRODUCTION}

Ritsumeikan Asia Pacific University (APU) is considered to be Japan's only true international university because it offers bilingual education and has well-balanced domestic-to-foreign student, faculty and staff ratios. It has a student population of 5,478 (as of
September 21, 2012) coming from 81 countries and regions and foreign students constitute around $44 \%$ of the total student body. Around $44 \%$ of its 167 fulltime faculty members are also foreigners from 27 countries and regions.

The University is located in Beppu City and was established in the year 2000 through public-private collaboration of Ritsumeikan Academy, Oita Prefecture, and Beppu City. It was aimed to be a hub for AsiaPacific studies, to create world class leaders in science, management and economics who could shape the future of Asia-Pacific region, and to promote international understanding, freedom, peace, humanity, and become sensitive to the needs of the time.

APU stakeholders put up a new and modern campus on top of Beppu hills, gathered world class academicians and started their mission with a few hundred freshmen students and world-class academicians in the year 2000 . The student population has been growing steadily since then and the university has been experimenting with various effective educational methodologies. Of course, effective education and teaching are of concern to all institutions and instructors, and there are many paradigms and methodologies related to this subject [1]. However, the challenges that APU has been facing as a private university is multifaceted - affluent students who are more interested in their distractions than in their studies, drop in the quality of incoming students due to the decline in youth population and the economic slowdown in Japan, large classrooms filled with nonhomogenous students, and high expectations at the exit point (i.e., upon graduation).

These are the main reasons why APU has shifted from conventional classroom teaching and has been using technologies, such as leaning management system (LMS), online file sharing, lecture recording, and ondemand streaming of recorded lectures, in order to establish an effective blended learning environment since its inception. The university has been investing significantly in information and communication technologies (ICT) to promote its curriculum, which has come to be noted by many governments and industries all over the globe. It has established an effective blended learning environment, total student support system and of a natural learning environment with its library transformed into 'Learning Commons' [2]. 
Even at the global level, the advancement in technology has been changing the way of teaching as well as learning since late 1990s. Recent statistics show that the use of web-based instruction as a supplement to face-to-face instruction or full online course has increased rapidly [1][3]. This is apparently because, students in online learning conditions perform better than those receiving face-to-face instruction, on average. Blended conditions often include additional learning time and instructional elements not available to students in control conditions.

Online learning overlaps with the broader category of distance learning, which encompasses earlier technologies such as correspondence courses, educational television and videoconferencing. Earlier studies of distance learning concluded that these technologies were not significantly different from regular classroom learning in terms of effectiveness. Policy-makers reasoned that if online instruction is no worse than traditional instruction in terms of student outcomes, then online education initiatives could be justified on the basis of cost efficiency or need to provide access to learners in settings where face-to-face instruction is not feasible [1].

The question of the relative efficacy of online and face-to-face instruction needs to be revisited, however, in light of today's online learning applications such as the Blackboard $(\mathrm{Bb})$, which takes advantage of a wide range of Web resources, including not only multimedia but also Web-based applications, mobile technologies, and new collaborations. These forms of online learning, which use software for delivering, tracking and managing lectures, are a far cry from the televised broadcasts and videoconferencing that characterized earlier generations of distance education. Today, LMS have become an integral component of the education systems in most universities and interest in hybrid approaches that blend in-class and online activities, is increasing [1]. Accordingly, 91\% of the approximately 4800 universities in the US have installed LMS.

Considering the above mentioned background information, objectives and significance of this paper can be summarized in the following manner:

\section{A. Research Issues}

The paper attempts to answer the following three questions:

1. What are some of the effective approaches to education in the $21^{\text {st }}$ century?

2. What are the impacts of integrating LMS technologies into our educational approaches and their underlying challenges?

3. What is the multimodal training approaches used at APU and how effective are they?

\section{B. Research Goal}

The first goal of this paper is to clearly show the reality that we face in the world education today which is done by means of showcasing APU as a private international university in Japan that caters to students of diverse background. The second goal is to emphasize the importance of learning through our multiple senses, tailoring of learning goals to student's attitude and ways to motivate students. The third goal is to identify some of the main challenges that are encountered in the process and demonstrate a working example of how they are being overcome at APU.

\section{Significance}

The significance of this paper lies in the fact that it aggressively and boldly examines problems that are common to most educational institutions, difficulties that are encountered when trying to address these problems and importance of continuous adaptations.

\section{Methodology}

This paper utilizes an exploratory-descriptive case study approach using multiple cross-case analyses. It initially applies qualitative analysis approach to secondary data to show positive impacts that adapting technology can have on education through survey analysis, and then applies the same method on its primary data in order to show how to maximize the learning outcomes and demonstrate the importance of total student support.

\section{E. Structure of the Paper}

The remaining sections of the paper examine how APU has been trying to improve the quality of its education through a multimodal approach towards teaching and learning. Through survey analysis, it also shows the ways in which Blackboard has been helping APU and other educational institutions around the world and foresees the future trends of educational technology. It then discusses characteristics that a successful $21^{\text {st }}$ century university must possess, together with underlying difficulties and necessary institutional policies and implementation procedures for attaining success. Finally, it demonstrates how APU is able to overcome many of the stated problems and the necessity of absolute commitment, an integrated multimodal approach towards enhancing the quality of teaching and learning, and a total student support and care system.

\section{Multimodal Training ApProach At APU}

The main philosophy behind APU's multimodal training approach is assurance of learning and quality of education. The aim is to give students a sense of satisfaction and achievement, encourage continuous selfdirected study, and train students to grow as human beings. An important issue has been to strengthen the quality of education with a focus on student's learning outcomes in accordance with the university's mission while heavily promoting student self-support initiatives. 


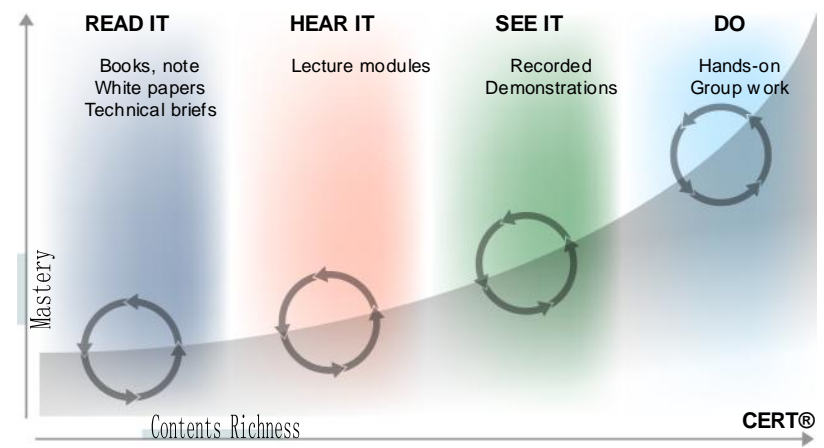

Figure 1. Multi-modal Learning Reinforcement

The multimodal teaching and learning approach at APU uses the fact that we learn through our various senses, hence, the more senses we use in the learning process, the faster and better we learn and retain new information. From a pedagogical point of view, merely (1) reading (books, lecture notes, etc.) and (2) listening (to lectures), as shown in the Fig. 1, will not produce sufficient results. However, by experiencing the process of (3) observing (i.e., recording lectures and re-watching them) and (4) acting (i.e., group work), students can achieve better results more quickly. We believe that the best way to ensure mastery and retention of a specific instructional subject is to present it to the students in multiple, increasingly engaging formats. Students read about a topic, hear about it, see it, and then put it into practice. They can repeat any step until they feel comfortable with the material [4-5].

This is the main reason why APU embraces blended learning platform wherein preparation for a lecture starts by downloading reading materials from the Blackboard system and participating in its discussion session, prior to the lecture. It has also equipped its classrooms with either fixed recording system or provides portable ones to those classrooms which are not equipped with a fixed one. Furthermore, as can be observed from Fig. 1, because there is a sharp rise in the mastery level of the learning curve at step (4), APU provides many venues for physical learning activities. Some of the major ones include the Language Learning Community (LLC) in the student dormitory, the Self Access Learning Center (SALC) in the Center for Language Education, the Crossover Advanced Program Laboratory (CAP-Lab) for CAP students, and a modern library ('Learning Commons') that is merged with multimedia room [6].

\section{A. Lecture Delivery via Smart Classrooms}

Shi et al. described and analyzed the design of a "Smart Classroom" [7], which was inspired by research on "Smart Space" at National Institute of Standards and Technology (NIST) [8]. Smart Spaces are work environments with embedded computers, information appliances, and multi-modal sensors allowing people to perform tasks efficiently by offering unprecedented levels of access to information and assistance from computers.

ALL APU classrooms and laboratories can be classified as "Smart Classrooms". However, their designs and intended use are subject-dependent and their allocations are usually made based on course contents, instructors' preferences and the way courses are envisioned to be handled. Each room is equipped with at least a lectern that houses a lecture delivery personal computer (PC), an interface for attaching a carry-in note-book, a document camera, and a control panel for the audio visual equipment (e.g. projector, sound system, etc.) of the room. Subjects that require extensive handson supervision during the delivery process (e.g., science and technology courses), or those that intensively use elearning approaches in the classrooms (e.g. language courses), or research-oriented subjects (e.g. seminars and research projects) are conducted in classrooms that also have individual student PCs. Table 1 shows a summary list of APU classrooms while Fig. 2 shows snapshots of some classrooms, multimedia laboratories, Information Technology (IT) infrastructures and resources.

TABLE I. SMART ClassRoOMS AT APU AND THEIR INDENTED USE

\begin{tabular}{|c|c|c|c|c|c|}
\hline Classroom Type & No. & $\begin{array}{c}\text { Student } \\
\text { Capacity }\end{array}$ & $\begin{array}{c}\text { No. Of } \\
\text { Student PC }\end{array}$ & Presentation Screen Type & Courses Conducted \\
\hline $\begin{array}{c}\text { IPS (Info Processing } \\
\text { Seminar) Rooms }\end{array}$ & 9 & 70 & 70 & $\begin{array}{c}\text { Personalized LCD Screens } \\
\text { (a pair of students shares one) }\end{array}$ & IT, ICT and MIS Courses \\
\hline $\begin{array}{c}\text { CAI (Computer Aided } \\
\text { Instruction) Rooms }\end{array}$ & 21 & 25 & 25 & $\begin{array}{c}\text { Personalized LCD Screens } \\
\text { a pair of students shares one) }\end{array}$ & $\begin{array}{c}\text { Language, Media and } \\
\text { Scied Management Course }\end{array}$ \\
\hline $\begin{array}{c}\text { Science and } \\
\text { Technology Seminar } \\
\text { Regular Seminar } \\
\text { Rooms }\end{array}$ & 20 & $8-10$ & $8-10$ & $\begin{array}{c}\text { Deskop Sharing } \\
\text { (via Windows Meeting }\end{array}$ & $\begin{array}{c}\text { Seminars and Supervised } \\
\text { Research/Thesis }\end{array}$ \\
\hline $\begin{array}{c}\text { Small Lecture Rooms } \\
\text { Onarge Screen }\end{array}$ & Regular Seminar Courses \\
\hline Medium Lecture Rooms & 81 & $18-25$ & 0 & One Large Screen & $\begin{array}{c}\text { Freshmen Workshop and } \\
\text { Debate Oriented Courses }\end{array}$ \\
\hline Large Lecture Rooms & 20 & $150-300$ & 0 & 4-6 Large Screens & Foundation and Elective \\
Courses
\end{tabular}




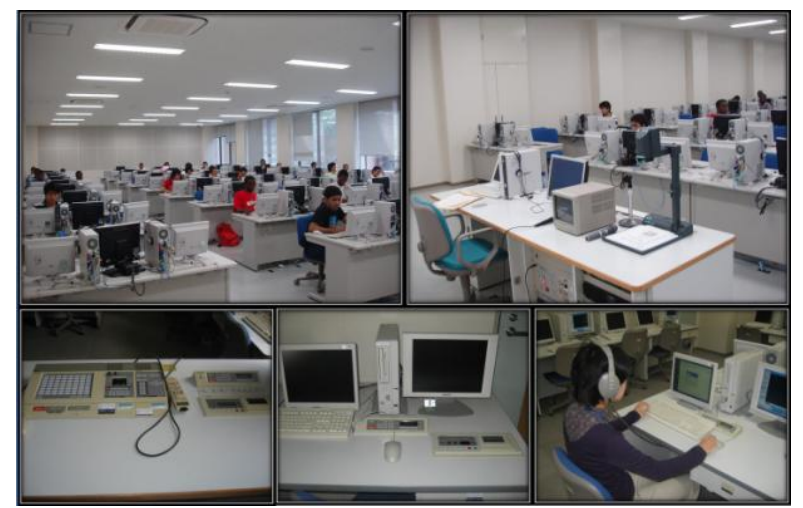

(a) IPS and CAI Classrooms

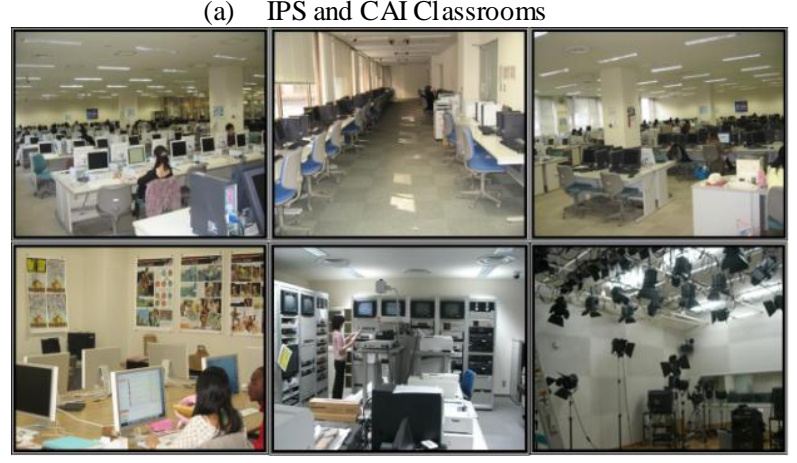

(c) Various Multimedia Laboratories

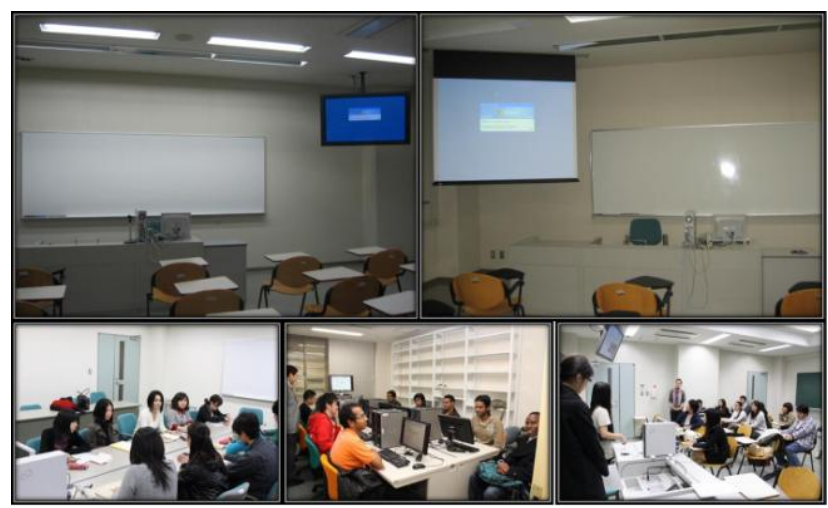

(b) ICT and Regular Classrooms

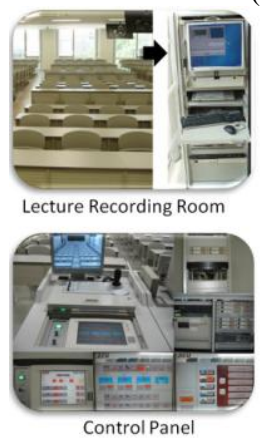

(d) IT Infrastructures and Resource

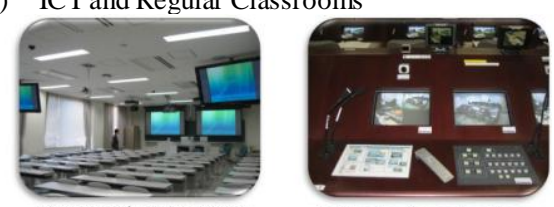

Distance Education Room Video Conferencing Room

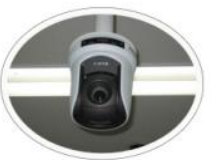

Student Camera

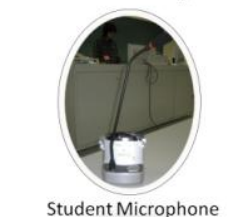

Figure 2. Snapshots of 'Smart Classrooms', various IT Infrastructures and Resources.

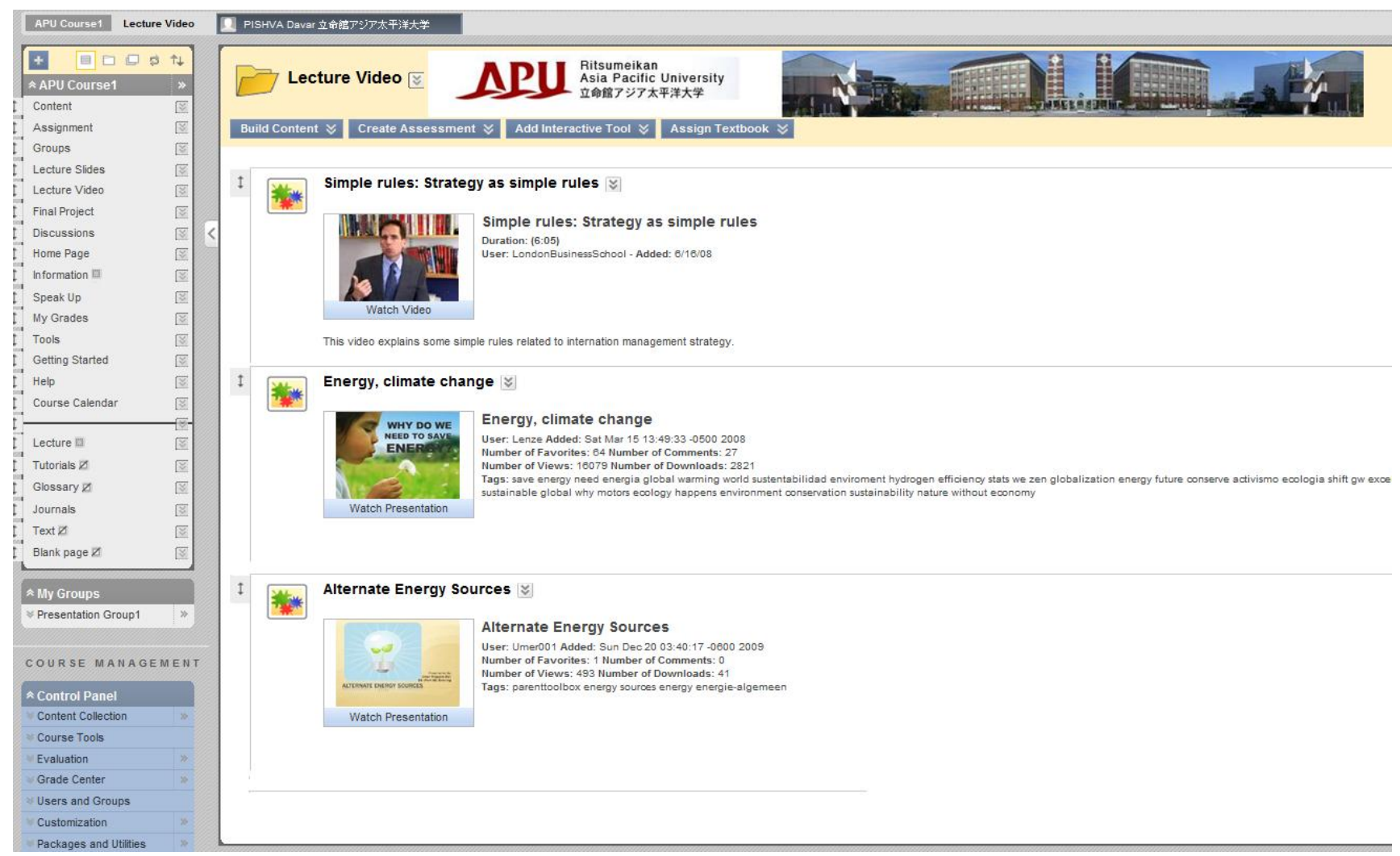

Figure 3. Instructor's course content page with YouTube links

\section{B. Recorded Demonstrations}

Class discussion and lectures can be recorded with fixed lecture recording systems which are built into the lectern in some classrooms or through portable ones settable in any other classrooms. Such recorded clips are uploaded to the multimedia streaming server and are available through the university's instructional website. Instructors can also provide a link to these recordings right in their Blackboard's course content page. 
Recorded demonstrations can also come in the form of commercial media like Digital Versatile Discs (DVDs), which are made available in the library at the request of the instructors. These media can be used in the library's multimedia booth in a personalized manner, or in the library's theatre corner for group/class use. Recently many media contents have become available in the form of online licenses and these can also be purchased through the library's budget and made available via the library website and the instructor's Blackboard course site. Such resources have proven to be very popular and effective, particularly in language courses.

Blackboard Learn 9.1 also provides an easy search and preview mechanism for relevant media contents on YouTube, right in the course content page. Instructors can easily find and preview course related video clips on YouTube and paste their links to the course content page. This is quite a new feature of the Blackboard and it is becoming attractive to many instructors. Fig. 3 shows an example of video clips links from YouTube on an instructor's course content page.

\section{Hands-on and Group Work}

Some courses like science and technology subjects (e.g., physics, biology, electronics, etc.) have accompanying laboratory sessions in which students apply the theoretical principles studied in the class into actual use in laboratories and then document their findings in formal reports. This approach significantly enhances student learning and also provides training in writing professional technical reports on findings. Other courses like programming, multimedia, etc. that require access to computer and internet are conducted in classrooms that are furnished with student PCs. Teaching assistants (TA) are also assigned to support faculty in large classes (e.g., in IPS) to ensure smooth operation of the hands-on component of the teaching sessions.

Freshmen workshop courses, which train students in basic writing, presentation, debate skills, and fieldwork studies, are mostly centered on group work. Each instructor is responsible for about 150-200 students and delivers a few key lectures at the beginning of the semester in large classrooms. Later, students are divided into groups of 4-6 students each with one student serving as a group leader. The groups are then allocated among small classrooms where group work activities take place in an informal setting with TA support. Every 2-3 groups are assigned a TA for personalized support and the instructor oversees the whole process. Towards the end of the semester, students are assembled back in a large classroom for formal presentation of their final projects. Other benefits that students receive from workshop courses are as follows:

1. Enhancement of students' analytical as well as observation skills which are necessary for studying at APU.
2. Improvement of cross-cultural communication skills.

3. Creation of a friendly and informal environment so as students get to know their classmates well and make many friends during their early stage at APU.

4. Acquaintance with the surrounding community where they will be spending at least a number of years while studying at the university.

5. Opportunity to conduct some community service during their field trips and get better accepted by the community.

APU also promotes self-directed, proactive learning to enhance the sense of achievement and satisfaction in learning and student development. That is why it provides many venues such as Language Lounge, LLC, SALC, CAP-Lab, and 'Learning Commons'. These provided an environment in which students can learn from each other and their peers in a natural fashion without feeling the pains of studying. As an example, snapshots of CAP-Lab environment are shown in Fig. 4.

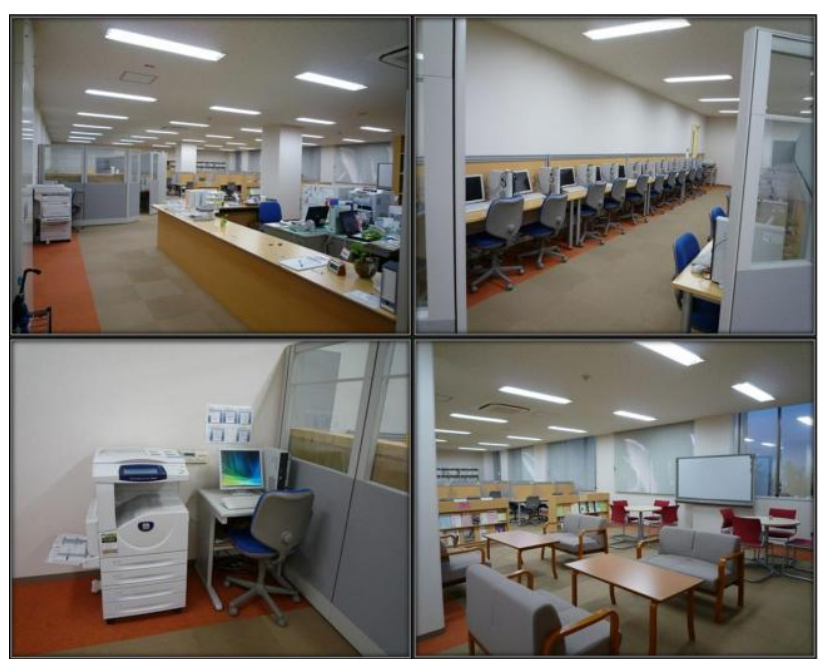

Figure 4. Snapshots of CAP-Lab environment at APU

\section{Total Student Support System}

APU, proud of its established diversity, creativity, innovation, high quality, and sensitivity to the needs of the time, decided to become a pioneer Japanese University and transformed its library in commemoration of its 10th anniversary in 2010 from a place that simply transmits knowledge to a place envisioned to create new knowledge. The whole library is divided into several diverse sections, each called a 'Pangaea' [9], and each 'Pangaea' is creatively designed to stimulate natural production of the required bits and pieces of knowledge - this newly created establishment is another example of APU's sensitivity to today's needs.

The newly established 'Learning Commons' are intended to provide a casual and friendly atmosphere to boost student motivation, strengthen multi-modal learning and emphasizes utilization of the space for new knowledge creation. Furthermore, through its numerous support programs (e.g. academic writing and advising, professional presentation and job hunting services, etc.), 
it aims to respond to the students' total needs by means of helping them concretize their vision, set clear objectives and career path goals, and guide them towards achieving their goals in their journey.

As a consequence, average occupancy rate of the library has increased by about $15 \%$ since the establishment. Furthermore, occupancy of some Pangaea, particularly those used for group discussions, e.g. Pangaea-1, usually exceeds their capacity limits in the afternoons.

It is worth mentioning that university libraries have traditionally functioned as centers for transmitting knowledge. However, with the rapid spread of the internet and massive increase in digital information, knowledge is being transmitted from many places by more convenient means. There is no doubt that in the near future, the traditional concept and function of the library will need a total overhaul. Some advanced North American universities have also transformed their libraries into 'Learning Commons' where the library premises are also being used for knowledge creation.

Fig. 5 shows snapshots of APU's 'Learning Commons'. APU has thus set another example of its innovative approach to high quality education by creating a proactive library with added learning and student support functions and positioning the library as a venue for "learning, exchange and growth".

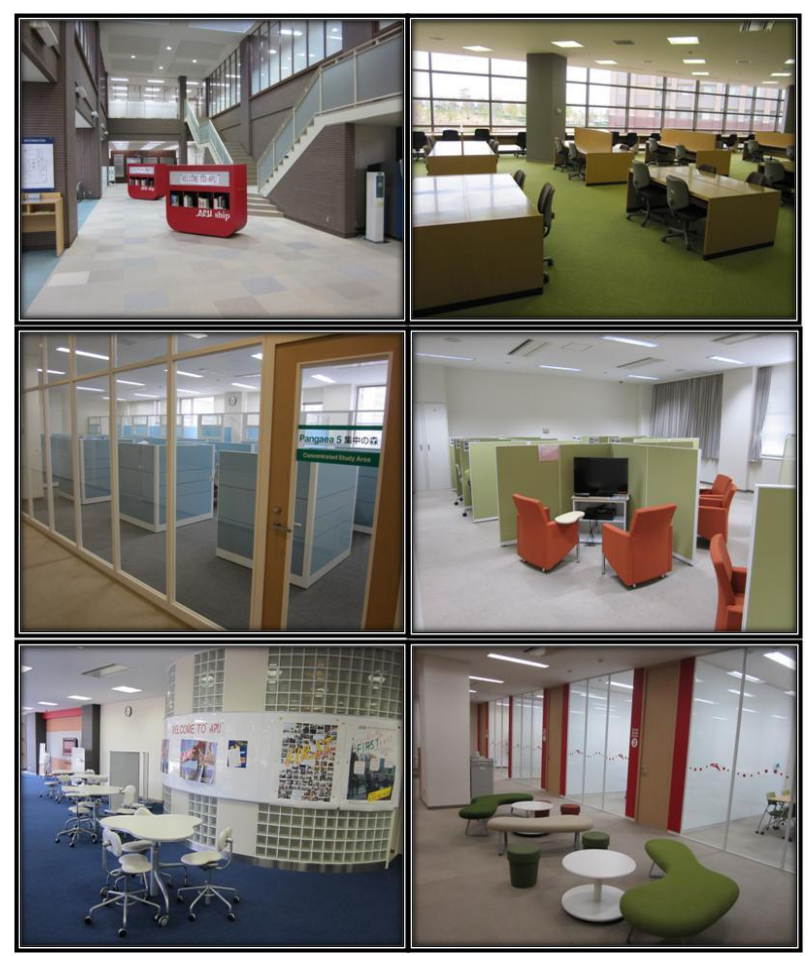

Figure 5. Snapshots of 'Learning Commons' at APU

\section{E. Adaption of e-Portfolio}

Electronic portfolio which is commonly referred to as e-Portfolio (or just portfolio) refers to a collection of electronic documents usually prepared for online distribution purposes. It connects to today's undergraduate students who feel comfortable communicating through multiple media by publishing their experience on sites such as Facebook, YouTube, and Flickr. In general, there are three main types of portfolio which are intended for:

- enriching student learning,

- promoting career development,

- supporting assessment processes, and their primary usage are:

- academic advising,

- institutional accreditation and developmental review,

- curricula development at the program level,

- career planning and development, and

- alumni development and lifelong learning.

Portfolio can help an institution facilitate and document authentic learning experiences and respond to the new era of accountability. It has been widely adopted in Europe, U.K. and U.S. as a learning and assessment tool. Some institutions are using them to collect and evaluate student work against institutional standards [10]

APU has been experimenting with different types of e-portfolios since 2009 and plan to adopt it as an integral component of its educational system in the near future. The goal is to be able to display students' achievements and progress, showcasing their experiences, and collecting their work and self-reflection from the time they entered to the university until their graduation.

\section{F. Web-based Integration}

As mentioned earlier, in order to establish an effective blended learning environment, APU has been using technologies like LMS, online file sharing, lecture recording, and on-demand streaming of recorded lectures since its inception in 2000. It initially employed a file transfer protocol (FTP) file server that holds two main folders, namely, an Instructional Materials folder (intended for course contents) and a Submit Report folder (for student submissions). Each main folder contains a sub-folder for every faculty member which in turn contains as many sub-folders as the courses handled by each faculty member. This system is still popular, especially in courses that require multiple file submissions like programming and web development, because of its easy drag and drop nature. However, it does not provide all the features and convenience of an LMS content and assignment folders (e.g., privacy and security).

APU has also been a Web Course Tools (WebCT) client from the year 2000 to 2007 and has been using the system to enhance its face-to-face education, particularly in language courses where there are many sections of the same course and in classes with large student populations [11]. In 2008, APU switched its LMS to Blackboard due to acquisition of the WebCT Company by Blackboard Inc. Blackboard's integrated product appears to be more user-friendly and supports many more useful functions. 
Since the author believes that an LMS technology like Blackboard Learn can serve as a powerful integration tool in a multimodal training approach [12], the rest of the paper is devoted to:

a. Gaining an understanding of Blackboard Learning System profiles.

b. Gaining an overview of the LMS market segment.

c. Exploring how Blackboard is helping educational institutions around the world and examining its current status.

d. Analyzing and studying the trend of the Virtual Learning Environment (VLE).

e. Discussing the requirements that a successful $21^{\text {st }}$ century university must meet in order to remain competitive.

f. Examining the adaptation and transitional difficulties, and necessary institutional policies and implementation procedures.

g. Showcasing APU's educational approaches in trying to successfully overcome the above mentioned challenges by making effective use of its available resources and streamlining its educational policy approaches.

\section{BLACKBOARD LEARN SYSTEM}

This is an LMS technology developed by Blackboard Inc. The company was founded in 1997; it is headquartered in Washington, D.C., with offices in North America, Europe, Asia, and Australia. It has been developing software to support educational institutions and has grown to become a global leader in enterprise technology and innovative solutions.

\section{A. Overview of Blackboard LMS}

The Blackboard learning management system, also defined as a virtual learning environment, is developed and maintained by Blackboard Inc [13]. It is a software product that enables educational institutions to create Internet-based learning programs. It has a customizable open architecture and a scalable design that allows integration with student information systems and authentication protocols. The software connects teachers, students, parents, and administrators via the Web, enabling Internet-based assignments, class websites, and online collaboration with classmates. The software also assists instructors with course administration and includes a content management system for creating and managing digital course content. Lecture notes, additional materials in note form, reading assignments, and library materials are distributed through the Blackboard. The Blackboard is also used to administer exams, conduct course evaluations, and submit students' grades [14]. Fig. 6 shows four different packages of the product.

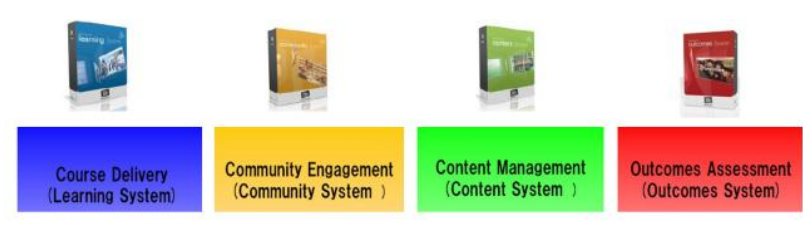

Figure 6. Four educational packages of the Blackboard Inc.

\section{B. Blackboard Share in the LMS Market}

As can be observed from Fig. 7, most of the LMS products have been created in late 1990s and are growing rapidly. Blackboard, despite having the biggest share among the market players as early as 1998, acquired Prometheus in 2001, WebCT in February 2006, and Angel Learning in May 2009. It now dominates the LMS market, having around 80\% share among US universities and over $50 \%$ among all the universities around the world.

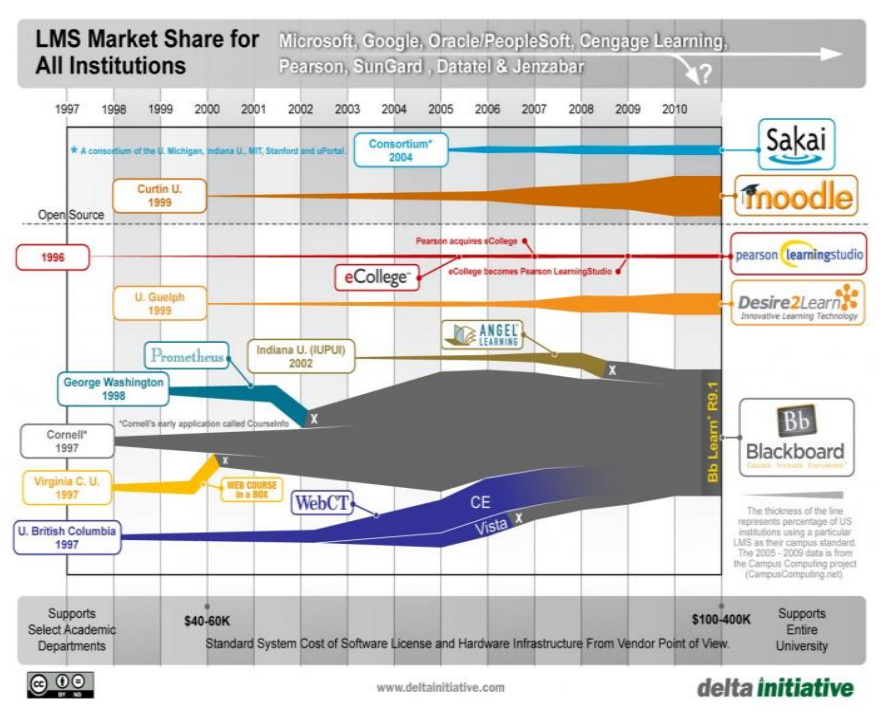

Figure 7. LMS Market

\section{How Blackboard is Assisting Educational Institutions around the World}

There are many survey results on Blackboard some of which compares it with other LMS products like Moodle [15]. As Blackboard Inc has grown into a huge Webbased LMS product and combined other LMS products, it has turned out to become a complex system with many different functions. Consequently, it has a steep learning curve and many complain about it $[16,17]$. However, numerous case studies and marketing research of Blackboard Inc show that their product is assisting many educational institutions in various aspects [18, 19], a summary of which is given in this section. The contents in parenthesis following each institution's name, indicates its location and starting year of implementation..

1) Arcadia University (Glenside, PA, USA; 2001): Arcadia uses Blackboard to connect and engage their students in their unique program called the First Year Study Abroad Experience (FYSAE), in which students begin their first year of college abroad. As students of such program have never stepped foot on Arcadia's 
campus, Arcadia uses Blackboard to connect and engage them with the campus so that they feel a part of the university. Students communicate through discussion boards about coursework and what to expect while overseas. Parents use discussion boards of their own to exchange information and discuss concerns about safety.

2) City of Sunderland College (UK; 2001): CSC uses Blackboard as a tool to address the challenges of retention and pass rates. Accordingly, they have achieved success rates well above the national average by embedding Blackboard in all of their subjects and pedagogy. Apparently, such efforts has brought about high-quality, accessible learning that enables learners to reach their full potential.

3) City University of Hong Kong (Kowloon, Hong Kong; 2002): In their efforts to engage all students regardless of location and as quickly as possible, CUHK replaced their multiple eLearning solutions with Blackboard to meet new course delivery, content management, and community engagement requirements. Accordingly, the replacement has been helping their student exchange program and first year student education.

4) Osaka University (Osaka, Japan; 2007): OU uses the Blackboard to enhance their face-to-face lectures and increase student engagement through a centralized location for classroom information.

5) University of Dundee (Dundee, Scotland; 2001): UD uses the Blackboard for managing Intellectual Property Rights by controlling and limiting access to licensed content.

6) University of Salzburg (Salzburg, Austria; 2001): US uses Blackboard to support their "Flexible Learning Initiative." Their students use Blackboard to attend tutorials and seminars, access reference material, and submit assignments online.

7) Servicio Nacional de Aprendizaje (SENA) (Colombia, South America; 2003): SENA uses the Blackboard to fulfill their obligation of providing access to education for all Colombians regardless of geographic location. They use the system for their face-to-face, hybrid, and fully online courses

\section{Current Status of Blackboard}

In early 2010, Blackboard Inc released Blackboard Learn 9.0, the next version of its Academic Suite Platform [20]. This version not only has enhanced existing features but is also heavily focused on implementing new web technologies and social and collaborative learning tools. It includes the recently developed Sakai and Moodle connectors (within the company's Building Blocks platform) which allow easier access to materials between Blackboard and the open-source systems. It also incorporates Web 2.0 and enhanced social learning capabilities including blogs, journals, group tools, and notification alerts. The Learn Suite also includes the company's Learning, Content,
Community, and Outcomes System. The present focus of Blackboard appears to be set on improved usability, staying current with web standards, and addressing users' needs.

By supporting the three major web browsers, Microsoft Internet Explorer (IE), Safari from Apple, and Mozilla Firefox, Blackboard has addressed the muchcomplained-about weak browser compatibility issue of the past [21]. By eliminating the annoying Java applets problem, another much-complained-about issue has been remedied [22]. Other highlighted features of Blackboard 9.0 include [20]:

- Facebook integration, which lets user access course information and receive announcement within the Facebook.

- SafeAssign, which comes handy for plagiarism detection and prevention.

- iGoogle-like user interface, which uses Asynchronous JavaScript (AJAX) technology to arrange components according to user interest.

- New navigation capabilities.

- Ease of integrability with other systems.

- Richer information at its homepage rather than the mere announcements of its predecessors [22].

In early 2011, Blackboard released an upgraded version, 9.1, in order to better support the traditional WebCT users. The following additional features are included:

- Section Merge

- Learning Module

- Wiki Function

- Assessment Manager

- Course Files

- Theme

- Bb Mobile Learn Integration.

\section{E. Future Trends}

The launch of Blackboard 9 series has resulted in a significant improvement in communication between users and system, between learners and learners, and between learners and instructor(s). As LMS has turned out to become a communication tool that assists educational endeavors, it is anticipated that advancement of collaborative tools and web services will continue further in the future.

Another potential area is the integration of LMS with mobile technology. With an array of smart phones and netbook releases, the number of mobile devices that can access internet has increased tremendously during the last 2 years. A remarkable device is iPhone from Apple Inc which has now became a standard smart phone and supported by Blackboard Learn 9 series. Netbooks on the other hand, which are also known as mini notebooks or subnotebooks, are light and inexpensive laptop computers suited for general computing and accessing Web-based applications. Since their focus has been on wireless connection capability and strong web browsing support, they will have tremendous effects on the LMS 
market. It is interesting to note that these devices, which started appearing in the market in late 2007, have been exhibiting amazing sales growth. Accordingly, a sales volume of less than 1 million units by end of 2007 increased to about 11.4 million units by the end of 2008 . The projected sales volume for 2009 was about 35 million units with an eventual increase to 139 million units by 2013 [22, 23].

Other LMS providers are also aware of the importance of LMS services provided via mobile devices. For instance, Desire2Learn Inc ("D2L"), a global provider of enterprise eLearning solutions, has also developed a mobile learning application called "Desire2Learn 2GO" which allows users to access course information from a BlackBerry mobile device. Moodle has also started supporting mobile devices, including all Japanese mobiles, iPhone, and iPod touch since 2009.

According to The Instructional Technology Council [24-26], the top 5 areas which will grow in LMS segment are:

- Online student organization and web service.

- Online counseling and advising.

- Online plagiarism evaluation.

- Online AudiolVideo streaming.

- Online textbook sales.

\section{Challenges AND POTENTIAL ADAPTION STRATEGIES}

As can be observed, during the past decade, the advancement of technology has created new educational environments and new approaches toward learning have emerged. It is evident that the traditional 'chalk and talk' way of learning is being replaced with a wide variety of learning styles and modes.

However, whereas young students are born in the era of mobile phones, internet and computers and feel comfortable with digital and information technology, many educators have grown up without the internet, mobile phones, or without even having computers as an integral part of their daily lives. In the digital world in which we live, our students can be considered as being 'Digital Natives', but many educators can be regarded as being 'Digital Immigrants' and like all immigrants, some adapt better than others to their environment.

Thus approaches to education in the $21^{\text {st }}$ century are going to be bold, challenging, creative, flexible, complex and ubiquitous (anywhere, anytime). Educational institutions must have a highly adaptable and flexible approach to teaching if they want to remain competitive. This is particularly true in the case of private universities like APU which has to charge expensive tuition fees for its economic sustainability and in a country like Japan which faces a shrinking student population and wherein economically affluent students are becoming picky and often more interested in their distractions than in their studies.
A successful $21^{\text {st }}$ century university must be a studentcentered institution that is unconstrained by time and place, operates simultaneously in a local and global context, constantly measures and communicates its progress, and continually renews its commitment to students, community, and economic competitiveness of the country. Its educational process should be treated like a continuous system analysis and design scenario, with students possessing numerous constraints (e.g., adventurousness, pickiness, affluence, etc.) as its input and graduate students who should satisfy numerous criteria (e.g. expectation of parents, future employer or graduate schools, etc.) as its output at the top level diagram of an educational system flowchart.

\section{A. Summary Advantages of Adapting Technology}

At the outset it should be mentioned that achieving the above educational system cannot be realized with the mere adaption of technology. It would need an absolute commitment, an integrated multimodal approach towards enhancing the quality of teaching and learning, and a total student support and care system. Nonetheless, proper adaption of technologies like Blackboard can play a vital role in the integration process and also serve as powerful tool to improve students' engagement, motivation, and life. This is because the Blackboard Learning System can help [27, 28]:

- Drive learner engagement through personalized experiences and active learning tools,

- Enhance instructor expertise by easily linking to supporting research and resources,

- Create powerful learning content using a variety of Web-based tools, links to outside resources and intuitive steps to incorporate existing material from off-the-shelf titles as well as proprietary training documents,

- Facilitate the creation of "learner networks" through participant interaction, small-group work and peer knowledge sharing,

- Enhance learners' critical thinking skills using interactive tools, and

- Evaluate progress using a rich set of evaluation and assessment capabilities.

\section{B. Key Adaptation Challenges and Ways Around Them}

The key adaptation difficulties are due to the fact that in the digital world in which we live, many educators are still 'Digital Immigrants' and the following are typical responses of those who cannot easily adapt to their new environments:

- Why do we need to use such technology?

- My time is very limited.

- How much work will it take to develop our courses?

- My courseware is already available on the network.

- Most of my work is in hard copy, etc. 
In general, however, the 'Digital Immigrants' can be classified into the following four categories:

- Pioneers - venturesome educators who are excited by the new technology and cannot wait to introduce new things.

- Early Adaptors - educators who are willing to learn and understand and willingly attend workshops and training sessions.

- Late Adaptors - educators who care about their teaching but not quite so much about technology.

- Very Late Adaptors - educators who need much encouragement and require more nurturing in the training arena.

With an institutional policy and a proper implementation strategy, educational institutions can indulge pioneers and 'Early Adaptors' early in the upgrade process and encourage them to help the rest of the community. However, the institutional policy should clearly identify must-adapt approaches versus nice-toadapt ones and the proper implementation strategy should include:

- Analysis of faculty needs.

- Identification of skill gaps among the faculty.

- Prioritized training (e.g., must-know vs. nice-toknow techniques).

- Pedagogy-based training rather than a featurebased approach.

- Delivery options (one-on-one vs. group sessions, online learning vs. in-person instruction?)

- Long term strategies (training is a long term investment - changes cannot occur overnight and often the benefits are not immediately obvious.)

\section{APPROACHES USED B Y APU}

The above mentioned challenges also exit in APU. For example, around $10 \%$ of its faculty falls into the pioneer class, $30 \%$ are early adapters, $40 \%$ late adapters and $20 \%$ very late adapters. Though since its inception in 2000, the pioneer class and many early adapters have adopted the technology; adoptions had been on a purely voluntary basis and were not tied to faculty assessment nor included in students' class evaluation forms. Furthermore, in the earlier days, trainings were provided by technical people and non-academicians who know the product's numerous features but unable to relate them faculty members' teaching pedagogies or pedagogy enhancements.

Nevertheless, in 2010 the university decided to upgrade its Blackboard server from a server that used to run Blackboard Learning System (CE Enterprise 6.2) and supported 300 simultaneous users to a server that runs Blackboard Learn 9.0 and supports 1,200 simultaneous users. One of the reasons behind the upgrade and simultaneous support of 1200 users was to encourage faculty members to conduct their examinations in an online manner. Results of a simple simulation showed that such an upgraded server could handle online exam administration requirements through effective use computer equipped classrooms such as IPS and CAI classrooms, shown on Table 1, during the examination periods.

Earlier experience of pioneer class APU faculty members had shown that administering online examination relieve faculty members from the burden test paper correction and distribution of their results. Furthermore, the experience also showed that speedy communication of test results to the students in a confidential manner increase their engagement and motivations in their studies.

Adoption of Blackboard is now included in faculty assessment and its effective adaptation to numerous teaching pedagogies have now become part of the university initiated faculty development (FD) program. Furthermore, faculty courses are automatically registered in their Blackboard site every quarter/semester and Blackboard training sessions have become a form of community service, provided from colleagues to colleagues, as well as a form of experience sharing event among the community members, rather than simply being a tutorial session on the product's features and usage, which had traditionally been delivered by technical or marketing people. The university also provides financial incentives to those faculty members who conduct a formal training session and shares their experiences with the APU community. The content of such training session is usually recorded and are made available for the faculty members. Colleagues who conduct the training also agree to serve as a help desk for their session during future inquiries.

In 2012 , around $40 \%$ of the faculty members were actively using the system and the university hopes to achieve an adaption of rate of $60 \%$ by the year 2013 and hopefully increase it to $80 \%$ by 2015 . In 2011, APU upgraded its Blackboard Learn to version 9.1 for the hope that its better support of WebCT users will further excite its pioneer and early adaptor users who had been using WebCT.

As part of its faculty development program in 2012, APU has created a division initiated program (DIP), coordinated by associate deans of the colleges and run by pioneer class faculty members. Through the DIP, faculty members are trained through experience sharing and by means of tailoring relevant functions of the Blackboard and other technologies to faculty members' teaching pedagogies. The following are some of the frequently conducted sessions:

- Introduction to Blackboard's Basic Tools.

- Effective adaption of Blackboard's discussion board to peer interaction and learning.

- Structured Learning Outside of Class through Blackboard.

- Online Collaboration and Interactive Grading using Google Docs and Blackboard tools.

- Academic writing and online plagiarism evaluation via Blackboard's SafeAssign function. 
- Supplementation of course contents with relevant videos.

- Conducting online Tests, Surveys and Quizzes via Blackboard.

- Role-Plays and Simulations in Class using Web and Computer technology.

The following sections briefly explain highlights of some of the above mentioned approaches.

\section{A. Example of Blackboard's Discussion Board Adaption to Peer Interaction and Learning.}

Most of the common and foundation courses in APU are held in Large Lecture Room, mentioned in Table 1, with each class having 150 students on the average. Typically, every class will consist of $10-20 \%$ top notch students, who are very keen in their studies; 40-50\% above average students, who take their studies somewhat seriously; $30-40 \%$ average students, who are either more interested in their distractions than in their studies or need more support.

Teaching in such classrooms often becomes challenging as instructors encounter difficulty in adjusting their lecture to different audience levels and also because of not being able to conduct an effective interactive lecture due to the large number of students. The author finds Blackboard Discussion Board quite useful in such settings. The idea is to upload a set of discussion questions on each topic to the Blackboard Discussion Board and assign class participation points for those who take part in the discussion. Furthermore, encourage students to identify topics they found important or difficult and ask them to share their points of views or questions with their peers and give participation points to any student who takes part in the discussion. Finally, by informing the students that 20 $30 \%$ of the exam questions will come from the contents of the discussion board; encourage students to actively get involved.

During the class, the author often adjusts its lecture to the majority group, e.g. the above average group, but challenges top notch students at their level and supports average students through the web. With this strategy, the author is able to indulge most of the students and ensures that everybody masters the essential part of the course. Although initial preparation of discussion questions and the author's contribution takes quite some times, teaching the same course from second time onwards becomes much more efficient. Furthermore, because the most recent version of the Blackboard automatically keeps track of course content access and participation, it makes it very easy for instructors to give recognition to those who are actively involved and push those who are not actively participating to work harder..

\section{B. Example of Adapting Google Docs and Blackboard Tools to Academic Writing and Students Research}

The author also finds Google Docs a nice platform to give academic writing support to those students who submit research reports and theses. Although students have many options to write their research results, options are relatively few when they wish to collaborate with their peers and instructors. Since 2009, the university has switched its email account to Gmail and Google Docs serves our needs quite well. Furthermore, by coupling Google Docs with Blackboard's SafeAssign, we can make our students to become more conscious about plagiarism.

Through SafeAssign, students can evaluate their work prior to their final submission to their instructors. Furthermore, SafeAssign enable us to create institutional databases and prevents students from copying and submitting previous graduates' work. Our strategy is to educate students on plagiarism, increase their awareness and academic writing skills rather than penalize them for plagiarized work. Our experience shows that when students have access to the same evaluation platform that will be used by their instructors to check their work, they tend to take things more seriously.

\section{Course Content Supplementation}

The author also finds Blackboard's Wiki is a useful tool for involving students in the process of creating and sharing course content. Through Wiki, students are encouraged to upload videos that complement lecture's content, edit and integrate several videos in a meaningful fashion. Through such schemes, instructors acts as facilitators as students create contents that they find most useful in appreciating a subject. Oftentimes, it appears as game like events and students learn in the process with feeling the pain of studying.

In technical courses, especially at graduate school where students come from a diverse background, students are encouraged to identify technical jargons and explain their meaning to their fellow students. They are then organized into course specific glossaries using Blackboard's Glossary tool, and allow students to crease a dictionary like annotated list of definitions. Through such scheme, not only we engage and deepen our students' learning in a specific field, but also help them improve their academic writing skills and proper referencing or citations techniques.

\section{SUMMARY AND CONCLUSIONS}

As such, APU's multimodal approach towards enhancing the quality of teaching and learning together with its total student support system has been producing good results. APU graduates have been achieving one of the highest employability rates in Japan (e.g., 95.6\% in $2008,90.2 \%$ in $2009,94.7 \%$ in 2010 , and $95.1 \%$ in 2011 ) or being admitted to topnotch graduate schools in Japan and abroad (e.g., Waseda, JAIST, CMU, etc.). However, to ensure continuity, the educational process should be treated like a continuous system analysis and design scenario as many external factors can have significant impacts on its input constraints (incoming students' condition) and output requirements (graduates' 
knowledge and ability). A successful $21^{\text {st }}$ century university must therefore be a student-centered institution and have a highly adaptable and flexible approach to teaching if it wants to remain competitive. This requires an absolute commitment, an integrated multimodal approach towards enhancing the quality of teaching and learning, and a total student support and care system.

Effective adaption of tools like Blackboard can indeed assist educational institutions around the world in many different ways, such as in face-to-face, hybrid, and online education. Considering that online instruction is no worse than traditional instruction in terms of student outcomes and the fact that interest in hybrid approaches has been increasing, Blackboard will continue to dominate LMS market. It will continue to evolve in a similar way that Microsoft Office Application has evolved. Users will eventually adjust to its steep learning curve and it will remain the choice LMS product, especially for institutions that can afford its rather expensive annual license cost. Open-source LMS products like Moodle will also continue to co-exist in a similar way that Open Office Application does, and may stay popular among cost-conscious institutions or those that posses in-house development and maintenance capabilities.

Advancement of technology during the last decade has led to the establishment of an active learning approach, allowing people to collaborate with each other in an effective fashion. There is no doubt that in the near future, LMS will become an essential tool for modern education. It will function as a portal for information and services, enabling people to stay connected and providing them with the necessary materials in a real time fashion.

\section{ACKNOWLEDGMENT}

The author would like to thank Dr. G.G.D. Nishantha and Mr. H. A. Dang for their valuable help and support on a related earlier work done together, Associate Dean Tsukada Shunso for DIP coordination and Dr. Rothman Steven for DIP training leadership. Special thanks are also due to APU Vice President Homma, who encouraged the author to document his work and volunteered to translate its earlier version into the Japanese language, a summary of which got published as an invited magazine article in the June and August 2011 issues of the 'University \& College Management' magazine.

\section{REFERENCES}

[1] B. Means, et al, "Evaluation of Evidence-Based Practices in Online Learning: A Meta-Analysis and Review of Online Learning Studies", U.S. Department of Education, Washington, D.C., 2009.

[2] "Learning Commons, University Library" http://www.library.illinois.edu/ugl/lc/.
[3] Hanover Research, "Trends in Global Distance Learning", http://www.hanoverresearch.com/wpcontent/uploads/2011/12/Trends-in-GlobalDistance-Learning-Membership.pdf, Feb 2011.

[4] D. Pishva, “The State-of-the-Art Remote Lecture System that Links University Campuses in Japan and America (Its Effectiveness and Future Challenges)", 22nd Annual Conference, Japan Society of Educational Information, p.8-11, (2006, in Japanese).

[5] D. Pishva, "Smart Classrooms Bring Top-Quality Education around the Globe", International Symposium on Applications and the Internet (IEEE SAINT2007), pp. 40-43, (2007).

[6] D. Pishva, "Multimodal Educational Approach at Ritsumeikan Asia Pacific University - Part (II)", University \& College Management Magazine Vol. 7, No. 5, pp. 25-30 (August 2011, in Japanese).

[7] Shi Y.C., Xie W.K., Xu G.Y.: "Smart Remote Classroom: Creating a Revolutionary Real-time Interactive Distance Learning System", Proceedings of International Conference on Web-based Learning 2002, Springer LNCS, 2436, p.130.

[8] “The NIST Smart Space Project", http://www.nist. gov/smartspace.

[9] "Pangaea", http://en.wikipedia.org/wiki/Pangaea.

[10] Michael Reese, Ron Levy, “Assessing the Future: E-Portfolio Trends, Uses, and Options in Higher Education", Research Bulletin, Vol. 2009, Issue 4, EDUCAUSE Center for Applied Research, pp. 1-12, (February 2009).

[11] G.G.D. Nishantha, D. Pishva, et al, "Current Usage and Future Trends of Learning Management Systems: A Case Study in Asia Pacific University”, International Conference of Technology, Education and Development (INTED 2009), pp. 948-958, (March 2009).

[12]D. Pishva, "Multimodal Educational Approach at Ritsumeikan Asia Pacific University - Part (I)", University \& College Management Magazine Vol. 7, No. 3, pp. 13-19 (June 2011, in Japanese).

[13]"Blackboard Learning System", http://en.wikipedia. org/wiki/Blackboard_Learning_System.

[14] "Blackboard's Web site for Asia Pacific" http://www.blackboard.com/us/index.aspx.

[15] Michael Machado, Eric Tao: "Blackboard vs. Moodle: comparing user experience of Learning Management System", Frontiers In Education Conference - Global Engineering: Knowledge Without Borders, Opportunities Without Passports, 2007. FIE '07. 37th Annual, pp. S4J-7 - S4J-12, (Oct. 2007). 
[16]"2008 APSC Faculty Blackboard Survey Results" http://www.portalinfo.utoronto.ca/apsc/2008survey. htm\#summary.

[17]"The University of North Dakota Spring 2008 Blackboard Learning management system student survey", http://www.cilt.und.nodak.edu/blackboard/ Bbsurveys/spring2008studentsurvey.pdf.

[18]"Blackboard Case Study", http://www. blackboard.com/us/index.aspx.

[19]“Blackboard Marketing Research", http://www. blackboard.com/us/index.aspx.

[20]David Nagel "Blackboard Bumps Learning Platform to 9.0", http://www.campustechnology.com/

Articles/2009/01/27/Blackboard-Bumps-LearningPlatform-to-Version-9.0.aspx.

[21]Patrick Ryan "Blackboard Learn 9.0 Supported Browsers \& Operating Systems", http://kb. blackboard.com/pages/view page. action?pageId $=455$ 81888.

[22] Keith Russell "Presentation Blackboard 9 - The next http://keithrussell.blogspot.com/2008/ 05/presentation-blackboard-9-next.html.

[23] Thom Holwerda "Netbook Market Sees Significant Growth", Dec 2008, http://www.osnews.com/story/ 20639/Netbook_Market_Sees_Significant_Growth.

[24] "The Instructional Technology Council 2008 Distance education survey results", http://www. itcnetwork.org/.

[25]"The Instructional Technology Council 2007 Distance education survey results", http://www. itcnetwork.org/.

[26]"The Instructional Technology Council 2006 Distance education survey results", http://www. itcnetwork.org/.

[27]Blackboard White Paper, "A view from the top: building the 21 st century campus", Blackboard Inc., pp. 1-39, January 2007.

[28]Blackboard White Paper, "Why Using a Learning Management System Alone May Miss the Learning Curve", Blackboard Inc., pp. 1-9, January 2008.

Dr. Pishva Davar is a professor in ICT at the College of Asia Pacific Studies, Ritsumeikan Asia Pacific University, Japan. He presently serves as the Dean of both College and Graduate School of Asia Pacific Studies and has been actively promoting adoption of innovative approaches to education. In teaching, he has been focusing on information security, technology management and carries out his lectures in an applied manner. In research, his current interests include biometrics, environmentally sound and ICT enhanced technologies and e-learning. Dr. Pishva received his $\mathrm{PhD}$ degree in System Engineering from Mie University, Japan. He is Secretary General of IAAPS (International Association for Asia Pacific Studies), Senior Member of IEEE, and a member of IEICE (Institute of Electronics Information \& Communication Engineers), IAAPS and University \& College Management Association. 